\title{
St. Catherine of Siena (1347-1380 AD), one of the earliest historic cases of altered gustatory perception in anorexia mirabilis
}

Francesco M. Galassi ${ }^{1 \#}$, Nicole Bender ${ }^{1{ }^{* *}}$, Michael E. Habicht ${ }^{1}$, Emanuele Armocida ${ }^{2}$, Fabrizio Toscano $^{3}$, David A. Menassa ${ }^{4}$, Matteo Cerri ${ }^{5}$

${ }^{1}$ Institute of Evolutionary Medicine, University of Zurich, Winterthurerstrasse 190, 8057 Zurich

${ }^{2}$ University of Parma, Parma, Italy.

${ }^{3}$ University of Siena, Post-Graduate School of Public Health, Siena, Italy

${ }^{4}$ Nuffield Department of Clinical Neurosciences, Division of Clinical Neurology, University of Oxford, OX3 9DU, UK

${ }^{5}$ Department of Biomedical and Neuromotor Sciences, University of Bologna, 40126 Bologna, Italy

\# Co-first authors

* Correspondence to Dr Nicole Bender, email: nicole.bender@iem.uzh.ch

\section{Email adresses}

Francesco M. Galassi : francesco.galassi@iem.uzh.ch

Nicole Bender : nicole.bender@iem.uzh.ch

Michael Habicht: michael.habicht@iem.uzh.ch

Emanuele Armocida: emanuele.armocida@studio.unibo.it

Fabrizio Toscano: fabrizio.toscano@student.unisi.it

David Menassa: david.menassa@,nden.ox.ac.uk

Matteo Cerri: matteo.cerri@unibo.it

\begin{abstract}
St. Catherine of Siena suffered from an extreme form of holy fasting, a condition classified as anorexia mirabilis (also known as inedia prodigiosa). Historical and medical scholarships alike have drawn a comparison between this primaeval type of anorexia with a relatively common form of eating disorder among young women in the modern world, anorexia nervosa. St. Catherine's condition was characterized by a disgust for sweet taste, a condition also described in anorexia nervosa, and characterized by specific neurophysiological changes in the brain. St. Catherine's
\end{abstract}


case may be considered one of the oldest veritable descriptions of altered gustation (dysgeusia). Moreover, a more compelling neurophysiological similarity between anorexia mirabilis and anorexia nervosa may be proposed.

\section{Main text}

St. Catherine of Siena (born Caterina di Giacomo di Benincasa, 1347-1380 AD) is venerated by the Catholic Church as one of the two Patron Saints of Italy and as Doctor of the Church. Her life and preaching were characterized by an extreme form of holy fasting, her diet being restricted to only water undiluted with wine and vegetables, a regimen of self-induced starvation which may well have played an important role in her ultimate demise at the young age of 33 [1]. Patently motivated by deep religious feelings and inspiration, her condition has been classified as anorexia mirabilis (also known as inedia prodigiosa), a retrospective diagnosis on which several authors have converged, irrespective of the etiology [1-2].

Historical and medical scholarships have drawn a comparison between this primaeval type of anorexia with a relatively common form of eating disorder among young women in the modern world, anorexia nervosa [1]. Anorexia nervosa, with a prevalence of $0.4-4.3 \%$ in young women in modern western societies, is typically characterized by a distorted body image, the desire to be thin and the feeling of being overweight despite an obvious underweight condition. The causes are likely to be a combination of genetic and social/psychologic determinants [3]. Anorexia nervosa appears to have been known since the Middle Ages, yet an absolutely confident distinction from anorexia mirabilis is difficult for this early historical period [1]. While anorexia mirabilis (propria) is no longer diagnosed in modern times, anorexia nervosa has been increasingly diagnosed during the course of the $20^{\text {th }}$ century. It remains however still unclear whether this is due to an increase in prevalence or an increase in awareness among professionals. Moreover, anecdotal reports of anorexia nervosa with a strong religious connotation - thus showing a certain overlap with anorexia mirabilis - can be found in the specialized psychiatric literature [4]. 
In the rich pathobiographical descriptions of St. Catherine's symptomatology collected by her early and later biographers, an element observed by Raymond of Capua (1330-1390 AD) stands out: the Dominican friar writes $[\mathrm{I}, 6.4]$ that her abstinence from food had been extreme, as much as her habit of having bitter foods and insipid drinks [amaros cibos et potus insipidos], that sweet foods had utterly become enemies of her bodily constitution [cuncta dulcia nociva suo corpori], and that she suffered a great deal from eating them [5]. This description - analysed through the historico-clinical lens [6] - can be regarded as trustworthy since Raymond of Capua, Catherine's confessor and disciple, had the privilege of being an eye witness of the most recondite aspects of the Saint's daily ascetic life. From a strictly neurophysiological perspective, it is noteworthy that TRP (Transient Receptor Potential) channels, especially TRPV1 and TRPM8, play a role both in the sense of taste, in pain perception and in the modulation of energy expenditure [7]. Some defects in the functioning of these channels may explain at least part of the symptoms found in the ancient sources.

Modern in vivo imaging methods in human and non-human primates locate primary gustatory cortex and thereupon the regulation of feeding behaviour to the rostral insula, the frontal operculum as well as the orbitofrontal cortex (OFC) [8]. In response to food images, functional magnetic resonance imaging studies show reduced activity in the anterior insula, the OFC and some cortical regions in anorexia nervosa [9]. Furthermore, the response to administered sucrose is reduced in the right anterior insula in patients with anorexia nervosa [10]. Additionally, anorexia nervosa patients show a higher disgust sensitivity for food compared with control patients. It has been suggested that disgust might originate as a defence mechanism against the ingestion of contaminated or poisonous foods [11]. As the anterior insula seems to be involved in interoception as well as in disgust processing, it is thinkable that the abnormal activity of the anterior insula triggered by sweet tastes reflects altered disgust processing, leading to an altered disgust sensitivity [12]. 
More and earlier examples of holy anorexic figures can be found in medieval literatures, most notably St. Clare of Assisi (1194 - 1253 AD). Although the symptomatological spectrum resembles Saint Catherine's, leading to a common retrospective diagnosis of anorexia mirabilis [13], a clear indication of dysgeusia cannot be confidently identified in the coeval sources. St. Catherine of Siena's case may thus be considered at least one of the oldest veritable descriptions of dysgeusia.

Moreover, on account of this, a more compelling palaeo-neurophysiological similarity between anorexia mirabilis and anorexia nervosa may be proposed.

\section{Acknowledgements}

The authors wish to thank the Mäxi Foundation (Switzerland) for supporting this research.

\section{Compliance with Ethical Standards}

This article does not contain any studies with human participants or animals performed by any of the authors.

Conflict of interest: The authors declare that they have no conflict of interest.

Data availability: the data used are referenced in the text.

\section{References}

1. Harris JC (2014). Anorexia nervosa and anorexia mirabilis: Miss K. R--and St Catherine Of Siena. JAMA Psychiatry 71(11):1212-1213.

2. Espi Forcen F, Espi Forcen C. (2015). The Practice of Holy Fasting in the Late Middle Ages: A Psychiatric Approach. J Nerv Ment Dis. 203(8):650-3.

3. Smink FRE, van Hoeken D, Hoek HW (2012) Epidemiology of Eating Disorders: Incidence, Prevalence and Mortality Rates. Curr Psychiatry Rep. 14(4):406-414.

4. Davis AA, Nguyen M (2014) A Case Study of Anorexia Nervosa Driven by Religious Sacrifice. Case Rep Psychiatry 2014:1-4. 
5. Nocentini S (Ed.) Raimondo da Capua. Legenda Maior sive legenda admirabilis virginis Catherine de Senis. [Critical edition] Sismel. Edizioni del Galluzzo, Firenze, p 157.

6. Galassi FM, Gelsi R (2015) Methodological limitations of an etiological framing of .569:(5)Ariarathes' goitre: response to Tekiner et al. J Endocrinol Invest 38

7. Abe J, Hosokawa H, Okazawa M, Kandachi M, Sawada Y, Yamanaka K, Matsumura K, Kobayashi S. (2005). TRPM8 protein localization in trigeminal ganglion and taste papillae. Brain Res Mol Brain Res. 136(1-2):91-8.

8. Schoenfeld M, Neuer G, Tempelmann C, Schussler K, Noesselt T, Hopf J, Hopf JM (2004) Functional magnetic resonance tomography correlates of taste perception in the human primary taste cortex. Neurosci 127: 347-353.

9. Uher R, Murphy T, Brammer M, Dalgleish T, Phillips M, Ng VW Andrew CM, Williams SC, Campbell IC, Treasure J (2004) Medial prefrontal cortex activity associated with symptom provocation in eating disorders. Am J Psychiatry 161: 1238-1246.

10. Oberndorfer TA, Frank GK, Simmons AN, Wagner A, McCurdy D, Fudge JL, Yang TT, Paulus MP, Kaye WH (2013) Altered insula response to sweet taste processing after recovery from anorexia and bulimia nervosa. Am J Psychiatry 170(10):1143-1151.

11. Chapman HA, Anderson AK (2012) Understanding disgust. Ann NY Acad Sci 1251:62-76.

12. Vicario CM (2013) Altered Insula Response to Sweet Taste Processing in Recovered Anorexia and Bulimia Nervosa: a Matter of Disgust Sensitivity? The Americal Journal of Psychiatry 170 (12):1497-1497.

13. Halverson JL. Contesting Christendom: Readings in Medieval Religion and Culture. Rowman \& Littlefield, 2008, p. 160. 